\title{
Neurologic Disorders Associated with Mitral Valve Prolapse
}

\author{
Alan C. Jackson
}

\begin{abstract}
Mitral valve prolapse has been reported to be associated with a variety of neurologic disorders, including cerebral ischemia, transient global amnesia, migraine, autonomic dysfunction, and psychiatric disease. The evidence supporting these associations and possible pathogenetic mechanisms are discussed. Some neurologic disorders may be direct complications of mitral valve prolapse, while others may occur as part of an underlying genetic defect or common link.
\end{abstract}

RÉSUMÉ: Affections neurologiques associées au prolapsus de la valvule mitrale Une variété d'affections neurologiques telles que l'ischémie cérébrale, l'amnésie globale transitoire, la migraine, la dysfonction du système nerveux autonome et des désordres psychiatriques, ont été décrites en association avec le prolapsus valvulaire mitral. Les données qui sont en faveur d'une telle association ainsi que les mécanismes pathogéniques éventuels sont discutés. Certaines affections neurologiques peuvent être une complication directe du prolapsus valvulaire mitral, alors que d'autres sont la manifestation d'un défaut génétique sousjacent ou lui sont communément associées.

Mitral valve prolapse (MVP) is a common cardiac abnormality, and has been the subject of numerous reports in the current medical literature. General aspects of the disorder have recently been reviewed. ${ }^{1-4}$ Over the past decade there has been considerable interest and, in some cases, controversy regarding the association of neurologic disorders and MVP. Some associations have not yet been firmly established, and the basis for others still remains quite speculative. The evidence for these associations will be reviewed.

\section{Diagnosis of Mitral Valve Prolapse}

In MVP one or both of the mitral valve leaflets prolapse (or balloon back) into the left atrium during left ventricular systole. The diagnostic criteria for MVP depend on the methods of study used, which may include auscultation, imaging techniques, or pathologic examination. The auscultatory features are one or more nonejection clicks and a late systolic murmur. Certain maneuvers, including changes in posture, may be helpful in eliciting these signs. MVP is identified by M-mode echocardio- graphy on the basis of abnormal posterior motion, either late systolic or pansystolic, of the mitral leaflets.' Limitations of $\mathrm{M}$-mode echocardiography include imaging in only the anteriorposterior plane, when the prolapse may occur in a superior direction, and false-positive findings due to abnormal orientation (in an inferior direction) of the transducer. ${ }^{5}$ Two-dimensional echocardiography has the advantage of visualizing more of the mitral leaflets, and appears to be a more sensitive technique for diagnosing MVP than M-mode echocardiography. ${ }^{5}$ There is an important subjective component in the interpretation of echocardiograms. Angiocardiography is invasive, the anterior mitral leaflet may not be well visualized, and there is considerable doubt about the exact criteria needed for diagnosis.' Some patients without auscultatory findings have prolapse on angiocardiography or echocardiography (silent MVP). It is not clear whether the pathologic substrate or risk of complications is different in these patients.

The basic pathologic feature of MVP is thickening of the spongiosa, a myxomatous connective tissue, with invasion and 
disruption of the fibrosa, which is composed of dense layers of collagen and forms the basic support of the leaflet. ${ }^{6}$ The defect in MVP may be due to "wear and tear", or there could be an altered composition of the collagen. ${ }^{7,8}$ The leaflets become voluminous, thickened, and elongated; the chordae tendineae are usually elongated and thickened. MVP occurs in patients of all ages. The prevalence is about $6 \%$ in both clinical and pathologic studies. ${ }^{6,9.10}$

\section{Cerebral and Retinal Ischemia}

Barnett and co-workers first recognized the association of MVP with cerebral ischemia. ${ }^{11,12}$ Barlow and Bosman ${ }^{13}$ had previously reported a woman with MVP who presented with transient left arm weakness at age 23. Retinal ischemic events have also been described. ${ }^{14}$ Barnett et $\mathrm{al}^{12}$ initially documented the association of MVP and cerebral ischemia in a series of patients that had careful evaluation for associated cardiac lesions. Subsequently, they performed a case-control study which substantiated the association. ${ }^{15}$ The prevalence of MVP was $40 \%$ in a group of 60 unselected patients, 45 years and younger, who had experienced cerebral and retinal ischemic events. Only six patients (10\%) had other potential reasons for ischemia. The prevalence of MVP was $6.8 \%$ in an age- and sex-matched control group. Scharf et al ${ }^{16}$ also found the prevalence of MVP was significantly higher in young patients with unexplained cerebral ischemia than in asymptomatic controls (Table 1). Egeblad and Sorensen ${ }^{17}$ were unable to confirm this association in a European case-control study. It is not clear whether this reflects a difference in their study populations or a difference in their diagnostic criteria for MVP.

Additional studies of the prevalence of MVP in cerebral ischemia are summarized in the Table. Various selection criteria were used in these studies. In general, a high prevalence of MVP (13-35\%) was found in young patients with cerebral ischemia. The prevalence was usually normal in older patients or in patients of unselected age. Because of the possibility of investigator bias, the uncontrolled studies should be considered of less consequence. Sandok and Giuliani ${ }^{26}$ found the prevalence rate for cerebral infarction was at least four times the expected rate in patients with MVP that were referred for echocardiography.
Thromboembolism from the abnormal mitral valve is the best supported mechanism for the association of MVP and ischemic events. There is clinical, angiographic, and pathologic evidence to support this mechanism. ${ }^{27}$ Cerebral and retinal symptoms and signs are focal, rather than diffuse. Retinal vascular occlusions have been observed in association with MVP. ${ }^{28} \mathrm{On}$ angiography, branch or "trunk" occlusions have been observed, with the subsequent disappearance of some of the lesions. Atheromata are not observed. Pomerance ${ }^{29}$ has noted fissuring and thrombus formation on myxomatous mitral valves. Aggregates of platelets and fibrin may form in the angle between the posterior leaflet of the mitral valve and the left atrial wall. ${ }^{30}$ In a patient with ischemic events, thrombus was demonstrated by two-dimensional echocardiography, and subsequently confirmed pathologically following surgery. ${ }^{31}$ Four fatal cases have been reported with postmortem examinations. ${ }^{32-35}$

The risk of stroke in young patients with MVP is low, and has been estimated at $1 / 6,000$ per year. ${ }^{36}$ At the present time there are not any good indicators to predict which individuals with MVP are prone to stroke. Two recent studies from European centers have suggested that more extensive valve involvement, with thickening of the mitral valve, may be associated with a greater risk of cerebral ischemia. ${ }^{37,38}$ Cerebral ischemia may also occur with MVP in older patients. However, it is more difficult to assess the importance of MVP in these patients because of the increased prevalence of atherosclerotic-thrombotic disease and other types of heart disease with increasing age. Recurrent ischemic events are not uncommon. Forty-four percent of young patients with cerebral ischemia had recurrent events at the time their MVP-associated ischemia was recognized. ${ }^{39}$ Empirical therapy with platelet antiaggregants has been recommended. ${ }^{40}$

\section{Familial Stroke}

The prevalence of MVP is increased in some families, and it may be inherited as an autosomal dominant trait. ${ }^{41}$ Rice et al ${ }^{42}$ reported four individuals in a 27 -member family with cerebral or retinal ischemia occurring at a young age. Ischemic events have also been described in a pair of monozygotic twins. ${ }^{43}$

Table 1: Mitral Valve Prolapse in Cerebral Ischemia

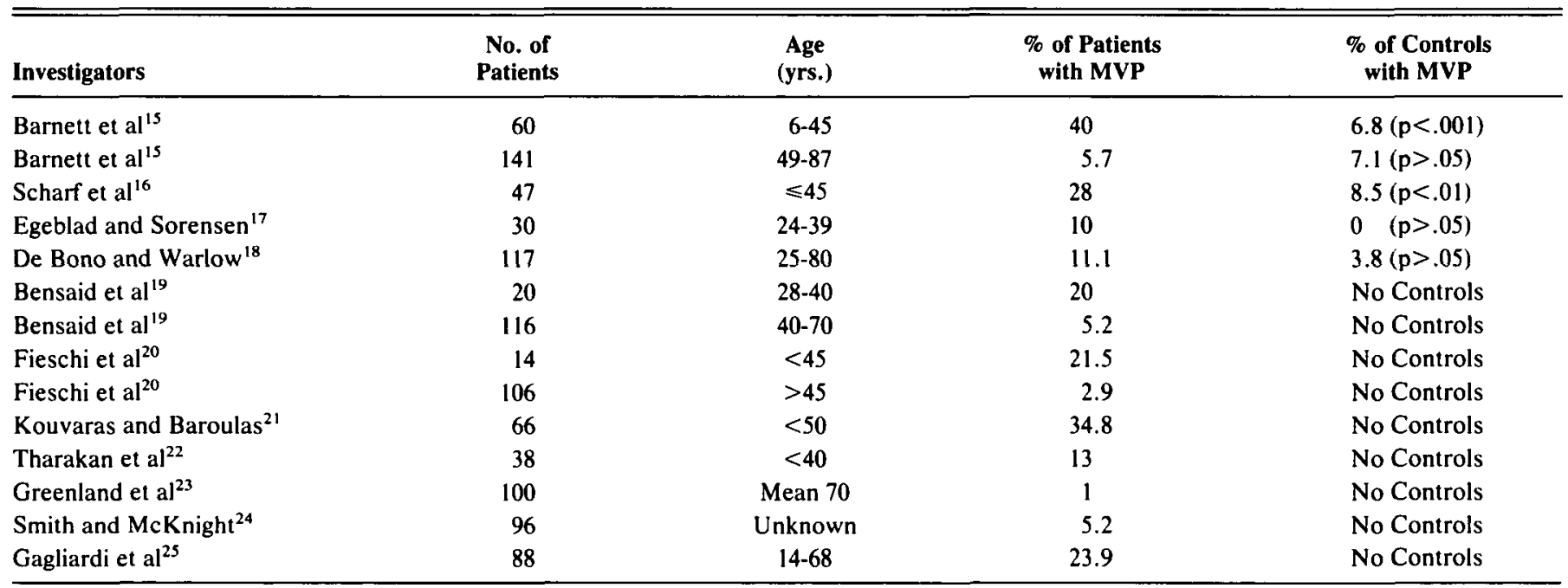




\section{Transient Global Amnesia}

Transient global amnesia is a clinical syndrome characterized by a sudden short-term memory defect and retrograde amnesia, usually lasting a few hours. ${ }^{44-46}$ Although the etiology is uncertain, a cerebral ischemic and an epileptogenic origin are the two main proposed theories. Many investigators believe ischemia of medial temporal structures is a common cause. Shuping et $\mathrm{al}^{46}$ described a patient with MVP and multiple recurrences of transient global amnesia. They ceased following mitral valve replacement. Jackson et $\mathrm{al}^{47}$ evaluated the prevalence of cardiac abnormalities in 53 transient global amnesia patients, and in the same number of age- and sex-matched control subjects. MVP was significantly more common in transient global amnesia patients $(24.5 \%)$ than controls $(7.5 \%)$. Recurrent episodes were common in the patients with MVP (46\%). MVP may produce transient global amnesia by a thromboembolic mechanism, as has been proposed in patients with MVP and cerebral ischemia.

\section{Infective Endocarditis}

MVP is a recognized cardiac lesion which predisposes to infective endocarditis. Cerebral embolism is the most common neurologic complication of bacterial endocarditis, occurring in $17 \%$ of 218 patients. ${ }^{48}$ Cerebral ischemia has been reported in 20-50\% of patients with MVP and infective endocarditis, and alpha-hemolytic streptococci are the most common causative organisms isolated. ${ }^{49.50}$ Evidence of infective endocarditis should be sought in all patients with MVP and ischemic events.

\section{Migraine}

Litman and Friedman ${ }^{51}$ reported migraine in $28 \%$ of 230 patients with MVP. Subsequently, Amat et $a^{52}$ reported MVP in $20 \%$ of vascular headache patients. Gamberini et $\mathrm{al}^{53}$ found MVP in $20 \%$ of common migraine patients, and migraine in $51 \%$ of patients with MVP. These three studies all lacked control groups. In a case-control study, Spence et $\mathrm{al}^{54}$ found MVP in $25 \%$ of patients with classic migraine and in $11 \%$ of control subjects. These studies support an association of MVP and migraine, but confirmation will require additional properly constructed studies. Platelet abnormalities have been described in migraine ${ }^{55.56}$ and MVP (see below), and both may have associated cerebral ischemia.

\section{Intracranial Aneurysms}

Jackson ${ }^{57}$ reported five patients with MVP and intracranial aneurysms, including three also with cerebral ischemic events. It is possible that the association in these case reports was by chance alone, and further study is needed to confirm the association. Mesodermal disturbances involving collagen and elastic tissue in the vasculature could provide a basis for both disorders. Abnormal collagen has been observed in both MVP and ruptured cerebral aneurysms. ${ }^{8,58}$ MVP has also been reported to be associated with von Willebrand syndromes and sickle cell disease, suggesting a linked connective tissue defect. ${ }^{59-61}$ Hence, there may be a common ground for certain cerebrovascular, cardiac, and hematologic disorders. ${ }^{62}$

\section{Seizures}

There have been occasional reports of patients with seizures and MVP. ${ }^{63-65}$ The association would be most understandable if the seizure disorder was related in some way to cerebral ischemia. At the present time, there is little evidence to support an important association.

\section{Muscular Dystrophies}

Winters et $\mathrm{al}^{66}$ reported the association of MVP and myotonic dystrophy in a single large kindred. Twenty-five relatives were screened, and they found 8 with both, 2 with myotonic dystrophy alone, and 1 with MVP alone. Two reports have described patients with the combination of myotonic dystrophy, MVP, and cerebral ischemia. ${ }^{33,67}$ MVP has also been reported in Duchenne muscular dystrophy. ${ }^{68.70}$ Sanyal et al ${ }^{70}$ speculate that MVP is an expression of the underlying cardiomyopathy characteristic of Duchenne muscular dystrophy, rather than due to isolated dystrophic involvement of the mitral valve leaflets.

\section{Platelet Activity}

A number of studies have provided evidence of platelet hyperreactivity in a significant number of MVP patients. ${ }^{16.71-74}$ Platelet coagulant hyperactivity, increased platelet factor 4 , increased B-thromboglobulin, and shortened platelet survival times have been demonstrated. However, Scharf et al ${ }^{16}$ did not find any significant difference between the elevated plasma B-thromboglobulin levels in young patients with cerebral ischemia with or without MVP. Platelet activation has been shown in asymptomatic MVP patients, as well as in MVP patients with thromboembolic events. The altered platelet activity may be a consequence of interaction of platelets with the abnormal myxomatous mitral valve. It has been speculated, but is unproven, that MVP patients with platelet hyper-reactivity may have an increased risk of thromboembolism.

\section{Autonomic Dysfunction}

Wooley ${ }^{75}$ has suggested that the autonomic dysfunction in MVP patients has been unrecognized for at least 120 years, and has masqueraded under such diagnoses as DaCosta's syndrome, soldiers heart, effort syndrome, and neurocirculatory asthenia. A number of specialized investigations have been performed on MVP patients (albeit often highly symptomatic) and controls in order to assess regulation of cardiovascular function. In some patients there is evidence of a hyperdynamic state, based on changes in various hemodynamic parameters and catecholamine levels in response to postural stress or isoproterenol infusion. ${ }^{76-81}$ Studies by Gaffney et $a l^{80}$ have shown that some MVP patients have vasoconstriction, tachycardia, elevated mean blood pressure on standing, and elevated plasma norepinephrine levels. The vasoconstriction may lead chronically to hypovolemia, and the volume of blood contained in the ballooning leaflets may reduce the ventricular and stroke volume. Although a large myxomatous valve could have a facilitative role, the autonomic disturbance could be the fundamental defect causing the hemodynamic abnormalities. Chesler et $\mathrm{al}^{82}$ feel the MVP patients studied have not been representative of patients with MVP in the general population. It is not clear how frequently autonomic dysfunction occurs in association with MVP, but it is well documented in some symptomatic MVP patients.

\section{Psychiatric Disorders}

Chronic anxiety neurosis, panic disorder, and agoraphobia are psychiatric disorders reported to be associated with MVP. 
Crowe $^{83}$ and Klein and Gorman ${ }^{84}$ have recently reviewed the association of MVP and panic disorder. A number of studies have shown an increased prevalence of MVP (15-50\%) in patients with panic attacks or agoraphobia. However, Hickey et $\mathrm{al}^{85}$ were unable to confirm an association of MVP and agoraphobia. It has been speculated that MVP may actually cause panic attacks. Susceptible anxious individuals may respond to MVP symptoms with fear and sympathetic arousal, leading to a further increase in their symptoms and a vicious circle. ${ }^{86} \mathrm{MVP}$ has also been reported in patients with primary disorders of sleep, including narcolepsy. ${ }^{87}$

\section{Sudden Death}

Patients with cardiac symptoms of MVP, such as dizziness or syncope, may present for neurologic evaluation. Although sudden death is a cardiac, rather than neurologic, complication of MVP, it is discussed here because warning symptoms may occasionally be recognized. Sudden death is rare in MVP. In many cases the clinical details are scanty or absent, and in some cases factors other than MVP could be incriminated ${ }^{88} \mathrm{~A}$ variety of arrhythmias are associated with MVP. ${ }^{89}$ It is likely that cardiac arrhythmias, especially ventricular fibrillation, are the cause of sudden, unexplained death. Chesler et $\mathrm{al}^{30}$ have found thrombotic lesions in the angle between the posterior leaflet and the left atrial wall containing aggregates of platelets and fibrin in some fatal cases. It is possible that arrhythmias could be caused by coronary thromboembolism.

The present problem is in identifying patients at risk of sudden death. Patients with ventricular ectopy or a convincing history of palpitations, presyncope, and syncope should be subjected to 24-hour ambulatory monitoring. Patients exhibiting dangerous arrhythmias should be maintained on antiarrhythmic drugs with regular monitoring. ${ }^{90}$ Dizziness and syncope in MVP patients are usually attributed to cardiac arrhythmias, but orthostatic hypotension is another possible cause. ${ }^{91}$

\section{Conclusions}

Patients with MVP are frequently seen in the practice of neurology. Some neurologic disorders have recognized associations with MVP. A neurologic disorder may be a direct complication of MVP, or the basis for the association may be an underlying genetic defect or common link. Evaluation of potential associations requires appropriate controls, since there is a substantial subjective element in the interpretation of echocardiograms which may introduce considerable bias. Pathologic studies should help to confirm specific associations in the future, and they may provide evidence supporting particular pathogenetic mechanisms. Markers for specific complications, neurologic or other, have not yet been well identified. In addition to clinical studies, identification of the fundamental defect in MVP, perhaps at the molecular level, may help to unravel the enigma surrounding this disorder.

\section{REFERENCES}

1. Cheitlin MD, Byrd RC. Prolapsed mitral valve: the commonest valve disease? Curr Probl Cardiol 1984; 8: 1-54.

2. Devereux RB, Perloff JK, Reichek $\mathbf{N}$ et al. Mitral valve prolapse. Circulation 1976; 54: 3-14.

3. Gravanis MB, Campbell WB. The syndrome of prolapse of the mitral valve, an etiologic and pathogenic enigma. Arch Pathol Lab Med 1982; 106: 369-374.
4. Wigle ED, Rakowski $\mathrm{H}$, Ranganathan $\mathrm{N}$ et al. Mitral valve prolapse. Annu Rev Med 1976; 27: 165-180.

5. Morganroth J, Mardelli TJ, Naito M et al. Apical cross-sectional echocardiography, standard for the diagnosis of idiopathic mitral valve prolapse syndrome. Chest 1981; 79: 23-28.

6. Lucas RV, Edwards JE. The floppy mitral valve. Curr Probl Cardiol $1982 ; 7: 1-48$

7. Cole WG, Chan D, Hickey AJ et al. Collagen composition of normal and myxomatous human mitral heart valves. Biochem J $1984 ; 219: 451-460$.

8. Hammer D, Leier CV, Baba $\mathrm{N}$ et al. Altered collagen composition in a prolapsing mitral valve with ruptured chordae tendineae. Am J Med 1979; 67: 863-866.

9. Davies MJ, Moore BP, Braimbridge MV. The floppy mitral valve, study of incidence, pathology, and complications in surgical, necropsy, and forensic material. Br Heart J 1978; 40: 468-481.

10. Savage DD, Garrison RJ, Devereux RB et al. Mitral valve prolapse in the general population. I. Epidemiologic features: the Framingham study. Am Heart J 1983; 106: 571-576.

11. Barnett HJM. Transient cerebral ischemia, pathogenesis, prognosis and management. Ann R Coll Physicians Surg Can 1974; 7: $153-173$.

12. Barnett HJM, Jones MW, Boughner DR et al. Cerebral ischemic events associated with prolapsing mitral valve. Arch Neurol 1976; 33: 777-782.

13. Barlow JB, Bosman CK. Aneurysmal protrusion of the posterior leaflet of the mitral valve, an auscultatory-electrocardiographic syndrome. Am Heart J 1966; 71: 166-178.

14. Wilson LA, Keeling PWN, Malcolm AD et al. Visual complications of mitral leaflet prolapse. Br Med J 1977; 2: 86-88.

15. Barnett HJM, Boughner DR, Taylor DW et al. Further evidence relating mitral-valve prolapse to cerebral ischemic events. $\mathrm{N}$ Engl J Med 1980; 302: 139-144.

16. Scharf RE, Hennerici M, Bluschke $V$ et al. Cerebral ischemia in young patients: is it associated with mitral valve prolapse and abnormal platelet activity in vivo? Stroke 1982; 13: 454-458.

17. Egeblad H, Sorensen PS. Prevalence of mitral valve prolapse in younger patients with cerebral ischaemic attacks. Acta Med Scand 1984; 216 : 385-391

18. De Bono DP, Warlow CP. Potential sources of emboli in patients with presumed transient cerebral or retinal ischemia. Lancet 1981: 1: 343-345.

19. Bensaid J, Cuisinier Y, Renaudin D et al. Accidents vasculaires cerebraux ischemiques: role etiologique du prolapus valulaire mitral. Nouv Presse Med 1980; 9: 1716.

20. Fieschi $C$, Francia A, Allori $L$ et al. Mitral valve prolapse as a risk factor for TIA, a study with echocardiography and dynamic ECG. Eur Neurol 1983; 22: 233-239.

21. Kouvaras G, Bacoulas G. Association of mitral valve prolapse with cerebral ischaemic events in the young and early middle-aged patient. Q J Med 1985; 55: 387-392.

22. Tharakan J, Ahuja GK, Manchanda SC et al. Mitral valve prolapse and cerebrovascular accidents in the young. Acta Neurol Scand 1982; 66: 295-302.

23. Greenland P, Knopman DS, Mikell FL et al. Echocardiography in diagnostic assessment of stroke. Ann Intern Med 1981;95:51-53.

24. Smith DL, McKnight TE. TIAs, completed strokes, and mitral valve prolapse. South Med J 1981; 74: 1454-1456.

25. Gagliardi R, Benvenuti $L$, Frosini $F$ et al. Frequency of echocardiographic abnormalities in patients with ischemia of the carotid territory-a preliminary report. Stroke 1985; 16: 118-120.

26. Sandok BA, Giuliani ER. Cerebral ischemic events in patients with mitral valve prolapse. Stroke $1982 ; 13: 448-450$.

27. Barnett HJM. Cardiac causes of cerebral ischemia. In: Toole JF, ed. Cerebrovascular Disorders. 3rd edition. New York: Raven Press, 1984: pp 174-177.

28. Caltrider ND, Irvine $\mathrm{AR}$, Kline $\mathrm{HJ}$ et al. Retinal emboli in patients with mitral valve prolapse. Am J Ophthalmol 1980; 90: 534-539.

29. Pomerance A. Ballooning deformity (mucoid degeneration) of atrioventricular valves. Br Heart J 1969; 31: 343-351.

30. Chesler E, King RA, Edwards JE. The myxomatous mitral valve and sudden death. Circulation 1983; 67: 632-639.

31. Donaldson RM, Emanuel RW, Earl CJ. The role of two-dimensional echocardiography in the detection of potentially embolic intra- 
cardiac masses in patients with cerebral ischaemia. J Neurol Neurosurg Psychiatry 1981; 44: 803-809.

32. Bramlet DA, Decker EL, Floyd WL. Nonbacterial thrombotic endocarditis as a cause of stroke in mitral valve prolapse. South Med J 1982; 75: 1133-1135.

33. Cook AW, Bird TD, Spence AM et al. Myotonic dystrophy, mitral-valve prolapse, and stroke (letter). Lancet 1978; 1:335-336.

34. Geyer SJ, Franzini DA. Myxomatous degeneration of the mitral valve complicated by nonbacterial thrombotic endocarditis with systemic embolization. Am J Clin Pathol 1979; 72: 489-492.

35. Schnee MA, Bucal AA. Fatal embolism in mitral valve prolapse. Chest 1983; 83: 285-287.

36. Hart RG, Easton JD. Mitral valve prolapse and cerebral infarction. Stroke 1982; 13: 429-430.

37. Barletta GA, Gagliardi $R$, Benvenuti $L$ et al. Cerebral ischemic attacks as a complication of aortic and mitral valve prolapse. Stroke $1985 ; 16: 219-223$.

38. Zenker G, Bone $G$, Ladurner $G$ et al. The myxomatous mitral valve, a risk factor for ischemic stroke in young patients? Eur Neurol 1985; 24: 82-84.

39. Jackson AC, Boughner DR, Barnett HJM. Mitral valve prolapse and cerebral ischemic events in young patients. Neurology (Cleveland) 1984; 34: 784-787.

40. Barnett HJM. Embolism in mitral valve prolapse. Annu Rev Med 1982; 33: 489-507.

41. Devereux RB, Brown WT. Genetics of mitral valve prolapse. Prog Med Genet 1983; 5: 139-161.

42. Rice GPA, Boughner DR, Stiller $\mathrm{C}$ et al. Familial stroke syndrome associated with mitral valve prolapse. Ann Neur 1980; 7: 130-134.

43. Fisher M, Budnitz E. Focal cerebral ischemia and mitral valve prolapse in monozygotic twins. Arch Intern Med 1983; 143:2180-2181.

44. Fisher CM, Adams RD. Transient global amnesia syndrome. Acta Neurol Scand 1964; 40(Suppl 9): 7-82.

45. Logan W, Sherman DG. Transient global amnesia. Stroke 1983; 14: 1005-1007.

46. Shuping JR, Rollison RD, Toole JF. Transient global amnesia. Ann Neurol 1980; 7: 281-285.

47. Jackson AC, Boughner DR, Bolton CF et al. Transient global amnesia associated with mitral valve prolapse (abstract). Neurology 1985; 35 (Suppl 1): 215.

48. Pruitt A, Rubin RH, Karchmer AW et al. Neurologic complications of bacterial endocarditis. Medicine (Baltimore) 1978; 57: 329-343.

49. Corrigall D, Bolen J, Hancock EW et al. Mitral valve prolapse and infective endocarditis. Am J Med 1977; 63: 215-222.

50. Hanson M, Conomy JP, Capraro J. Mitral valve prolapse, cerebral ischemia, and bacterial endocarditis (abstract). Neurology 1982; 32 (Suppl 2): A88.

51. Litman GI, Friedman HM. Migraine and the mitral valve prolapse syndrome. Am Heart J 1978; 96: 610-614.

52. Amat G, Louis PJ, Loisy $\mathrm{C}$ et al. Migraine and the mitral valve prolapse syndrome. Adv Neurol 1982; 33: 27-29.

53. Gamberini G, D'Alessandro R, Labriola E et al. Further evidence on the association of mitral valve prolapse and migraine. Headache $1984 ; 24: 39-40$.

54. Spence JD, Wong DG, Melendez LJ et al. Increased prevalence of mitral valve prolapse in patients with migraine. Can Med Assoc J 1984; 131: 1457-1460.

55. Deshmukh SV, Meyer JS. Cyclic changes in platelet dynamics and the pathogenesis and prophylaxis of migraine. Headache 1977; 17: $101-108$.

56. Gawel M, Burkitt M, Rose FC. The platelet release reaction during migraine attacks. Headache 1979; 19: 323-327.

57. Jackson AC. Association of mitral valve prolapse and intracranial aneurysms. South Med J 1983; 76: 712-713.

58. Neil-Dwyer G, Bartlett JR, Nicholls AC et al. Collagen deficiency and ruptured cerebral aneurysms: a clinical and biochemical study. J Neurosurg 1983; 59: 16-20.

59. Lippman SM, Abergel RP, Ginzton LE et al. Mitral valve prolapse in sickle cell disease: manifestation of a generalized connective tissue disorder. Am J Hematol 1985; 19: 1-12.

60. Lippman SM, Ginzton LE, Thigpen T et al. Mitral valve prolapse in sickle cell disease, presumptive evidence for a linked connective tissue disorder. Arch Intern Med 1985; 145: 435-438.
61. Pickering NJ, Brody JI, Barrett MJ. Von Willebrand syndromes and mitral-valve prolapse, linked mesenchymal dysplasia. $\mathbf{N}$ Engl J Med 1981; 305: 131-134.

62. Andrews RJ. Collagen in cerebral aneurysms, mitral valve prolapse, and von Willebrand syndrome (letter). Stroke 1984; 15: 917.

63. Hanson MR, Conomy JP, Hodgman JR. Brain events associated with mitral valve prolapse. Stroke 1980; 11: 499-506.

64. Smirniotopoulos TT, Sheppard GL. Mitral-valve prolapse presenting with seizures: case report. Va Med 1984; 111: 699-700.

65. Taylor D, Horenstein S, Williams G et al. Syncope, seizure, and stroke in the mitral valve prolapse syndrome. Trans Am Neurol Assoc 1979; 104: 114-116.

66. Winters SJ, Schreiner B, Griggs RC et al. Familial mitral valve prolapse and myotonic dystrophy. Ann Intern Med 1976; 85: 19-22.

67. Morris LK, Cuetter AC, Gunderson CH. Myotonic dystrophy, mitral valve prolapse, and cerebral embolism. Stroke 1982; 13: 93-94.

68. Biddison JH, Dembo DH, Spalt $\mathrm{H}$ et al. Familial occurrence of mitral valve prolapse in X-linked muscular dystrophy. Circulation 1979; 59: 1299-1304.

69. Reeves W, Griggs R, Nanda NC et al. Echocardiographic demonstration of mitral valve prolapse in muscular dystrophy (abstract). Circulation 1976; 54 (Suppl II): 97.

70. Sanyal SK, Leung RKF, Tierney RC et al. Mitral valve prolapse syndrome in children with Duchenne's progressive muscular dystrophy. Pediatrics 1979; 63: 116-123.

71. Arocha F, Diez-Ewald M, Durango AI et al. Platelet activity in mitral valve prolapse: a study of platelet aggregation, malondialdehyde production, and plasma $\beta$-thromboglobulin. Am J Hematol 1985; 19: 21-25.

72. Fisher $M$, Weiner $B$, Ockene IS et al. Platelet activation and mitral valve prolapse. Neurology (Cleveland) 1983; 33: 384-386.

73. Steele $P$, Weily $H$, Rainwater $J$ et al. Platelet survival time and thromboembolism in patients with mitral valve prolapse. Circulation $1979 ; 60: 43-45$.

74. Walsh PN, Kansu TA, Corbett JJ et al. Platelets, thromboembolism and mitral valve prolapse. Circulation 1981; 63: 552-559.

75. Wooley CF. Where are the diseases of yesteryear? DaCosta's syndrome, soldiers heart, the effort syndrome, neurocirculatory asthenia-and the mitral valve prolapse syndrome. Circulation 1976; 53: 749-751.

76. Boudoulas H, Reynolds JC, Mazzaferri E et al. Metabolic studies in mitral valve prolapse syndrome, a neuroendocrine-cardiovascular process. Circulation 1980; 61: 1200-1205.

77. Boudoulas H, Reynolds JC, Mazzaferri E et al. Mitral valve prolapse syndrome: the effect of adrenergic stimulation. J Am Coll Cardiol 1983; 2: 638-644.

78. Coghlan $\mathrm{HC}$, Phares $\mathrm{P}$, Cowley $\mathrm{M}$ et al. Dysautonomia in mitral valve prolapse. Am J Med 1979; 67: 236-244.

79. Gaffney FA, Karlsson ES, Campbell W et al. Autonomic dysfunction in women with mitral valve prolapse syndrome. Circulation 1979; 59: 894-901.

80. Gaffney FA, Bastian BC, Lane LB et al. Abnormal cardiovascular regulation in the mitral valve prolapse syndrome. Am J Cardiol 1983; 52: 316-320.

81. Pasternac A, Tubau JF, Puddu PE et al. Increased plasma catecholamine levels in patients with symptomatic mitral valve prolapse. Am J Med 1982; 73: 783-790.

82. Chesler E, Weir EK, Braatz GA et al. Normal catecholamine and hemodynamic responses to orthostatic tilt in subjects with mitral valve prolapse, correlation with psychologic testing. Am J Med 1985; 78: 754-760.

83. Crowe RR. Mitral valve prolapse and panic disorder. Psychiatry Clin North Am 1985; 8: 63-71.

84. Klein DF, Gorman JM. Panic disorders and mitral valve prolapse. J Clin Psychiatry Monograph 1984; 2: 14-17.

85. Hickey AJ, Andrews G, Wilcken DEL. Independence of mitral valve prolapse and neurosis. Br Heart J 1983; 50: 333-336.

86. Kantor JS, Zitrin CM, Zeldis SM. Mitral valve prolapse syndrome in agoraphobic patients. Am J Psychiatry 1980; 137: 467-469.

87. Clark RW, Boudoulas H, Schaal SF et al. Adrenergic hyperactivity and cardiac abnormality in primary disorders of sleep. Neurology 1980; 30: 113-119. 
88. Barlow JB, Pocock WA. The mitral valve prolapse enigma-two decades later. Mod Concepts Cardiovasc Dis 1984; 53: 13-17.

89. Swartz MH, Teichholz LE, Donoso E. Mitral valve prolapse, a review of associated arrhythmias. Am J Med 1977; 62: 377-389.

90. Pocock WA, Bosman CK, Chesler E et al. Sudden death in primary mitral valve prolapse. Am Heart J 1984; 107: 378-382.
91. Santos AD, Mathew PK, Hilal A et al. Orthostatic hypotension: a commonly unrecognized cause of symptoms in mitral valve prolapse. Am J Med 1981; 71: 746-750. 